\title{
Fifth Annual Conference on Atomic Spectroscopy
}

\section{Lund, 10-13 July 1973}

The thousand-year-old City of Lund in the south of Sweden provides excellent facilites for conferences. Inevitably, many participants in the 5th Annual Conference of the European Group for Atomic Spectroscopy must have come to this conclusion. They attended a conference that was organized by colleagues from the Atomic Physics Laboratory of the Lund Institute of Technology and from the Atomic Spectroscopy Laboratory of the University of Lund.

From 10-13 July 1973, 260 physicists came together in the Sparta Centre; among them was the first, and now honorary, president of EGAS, A. Kastler from Paris. In his opening address, he reminded the audience of the Rydberg Conference on Atomic Spectroscopy, also held in Lund, in 1954. B. Edlén from Lund, resigning president of EGAS, welcomed the participants; in the first place, those among them who also attended the Rydberg Conference; secondly, the many newcomers; and, finally, all acquaintances of previous conferences.
Seven invited papers reviewed almost the entire field covered by EGAS : theory was represented by Relativistic Effects in Atomic Spectra from S. Feneuille, Orsay; N. Spector, Yavne, presented New Trends in Rare-Earth Analysis and A. Gabriel, Culham, showed the relation between Atomic Spectroscopy and Astrophysics in High-Charged lons in Astrophysics, illustrated with spectrograms from the corona with wavelengths down to $15 \AA$. The emphasis, however, was laid on modern spectroscopic techniques with 4 invited papers: Applications of Synchrotron Radiation to Atomic, Molecular and Solid State Spectroscopy from K. Codling, Reading ; Applications of Tunable Lasers to Atomic Spectroscopy from H. Walther, Cologne; Recent Progress in Studies of Atomic Spectra and Transition Probabilities by Beam-Foil Spectroscopy from I. Martinson, Stockholm; and Fine structure, Hyperíine structure and Lamb Shift Measurements by the Beam Foil Technique from J. Andrä, Berlin. The invited papers, which will be published in
Physica Scripta were each followed by contributed papers in the same field. The number of contributed papers was 115 .

Round-table discussions enabled participants to bring problems to the fore that could be interesting to others and that, maybe, could be solved. Topics were: Tunable Laser Spectroscopy, Isotope Shift, R.F. Spectroscopy and Term Analysis. The last mentioned resulted in a report on the progress of the analysis of spectra, achieved in 13 institutes. Visitors to the laboratories of both organizing groups admired the collection of 10 long-focal-distance spectrographs, covering the region $50 \AA-4 \mu$, used with various experiments.

Scientific activities were interrupted by receptions in 'Stadshellen' by the City of Lund and in the University building by the University of Lund. Many participants enjoyed the Conference Dinner Party and the postconference bus trip.

During the conference, business meetings of EGAS were held including the General Assembly. Three new board members were elected for a period of three years; the resigning president, B. Edlén from Lund was succeeded by A. Steudel from Hanover.

\section{E. Meinders}

\section{Pollution in the Air}

SCORER, R.S. (Routledge \& Kegan Paul, London, 1973) 144 pages + Index. £ 2.75

To read Pollution in the Air is to appreciate, on the one hand, how much scope there is for environmental physics and to be astonished, on the other hand, at the vast sums committed by politicians for detecting and cleaning air 'pollutants' whose harmfulness has never been justified. As a professional worker in theoretical mechanics and an active politician himself, R.S. Scorer is well placed to address both scientists and politicians.

His longest chapter on 'A Theory of Anti-Pollution Law' contains many gems. The ten arguments he gives against establishment of ambient air quality standards have been shown to be borne out in practice in the U.S.A., where enforcement of the Clean Air Act of 1970 by the Environmental Protection Agency has led to increasingly complex legal difficulties.

The most revealing moments are where Scorer exposes the opportunism of those scientists who are guilty of scare-mongering. Lead in petrol, carbon monoxide in exhaust fumes, mercury in fish, DDT dangers, and supersonic transport effects on the stratosphere are all declared to be 'non-problems' on subsequent analysis. According to Scorer,

We ought to keep our attention on smoking, and on nuclear weapons which cannot possibly be used for a purpose which would subsequently be approved of.'

However, he reserves his last words for the emerging energy crisis with an appeal not to be simple-minded about the possibilities of nuclear power. There are serious problems of disposal of radioactive wastes in fission, and even if fusion energy is controlled, the radioactive by-products have still to be established. It is clear that the ingenuity and talents of physicists will be much in demand by governments faced with increasing pressure for action on the energy crisis. However, the message from this book is also clear - scientists should take every step to keep the public directly informed in terms it can understand.

\section{Research, Science and Education}

trom page 3)

adopt one is a sign of their willingness to act as a community. R \& D is seen to have two central themes:

(i) Innovation in response to social requirements to meet the needs of protecting the environment, health, education, urban development - that is, in general, improving the quality of like.

(ii) Innovation in industry to maintain and increase capacity and to raise the level of technology.

\section{Scientific and technical information}

From the programme, it appears that the Commission will be preparing to devote considerable efforts to improving the effective circulation of scientific and technical information. The Commissioner had been impressed by somewhat pessimistic expert opinion that data processing will raise intractable problems of a social, political and economic nature, so he proposed the setting up of an efficient and justifiable system for the management and development of information as a primary objective. 